\title{
CHEMOSPHERE
}

\section{Effects of feed solutions on refuse hydrolysis and landfill leachate characteristics}

\author{
Pin-Jing He ${ }^{\mathrm{a}, *}$, Li-Ming Shao ${ }^{\mathrm{a}}$, Xian $\mathrm{Qu}^{\mathrm{a}}$, Guo-Jian Li ${ }^{\mathrm{a}}$, Duu-Jong Lee ${ }^{\mathrm{b}}$ \\ a State Key Laboratory of Pollution Control and Reclamation, Department of Environmental Engineering, \\ Tongji University, 1239 Siping Road, Shanghai 200092, PR China \\ b Department of Chemical Engineering, National Taiwan University, Taipei 10617, Taiwan, ROC
}

Received 22 March 2004; received in revised form 4 October 2004; accepted 25 October 2004

\begin{abstract}
Tap water, aerobically pre-treated leachate, and anaerobically pre-treated leachate, were each fed into the top of a series of three simulated landfills columns, filled with municipal solid waste collected in Shanghai, China. Changes in leachate, including $\mathrm{pH}$, total organic carbon (TOC), and volatile fatty acids (VFAs), and the produced biogas were monitored over time. The tap-water-fed columns had a low hydrolysis rate that yielded an acidic environment $(\mathrm{pH}$ 4.8-5.4) in the leachate that inhibited methanogenesis reaction in the refuse. When aerobically pre-treated leachate was fed into the columns, the hydrolysis rate of total organic carbon fluctuated between 200 and $400 \mathrm{mg} \mathrm{d}^{-1}$ and methanogenesis in the refuse column was only partly activated. The hydrolysis rate of refuse fed with anaerobically pre-treated leachate was the highest among the three solutions. The high alkaline levels of the anaerobically pre-treated leachate and its methanogenic bacteria led to an early activation of methanogenesis in the refuse columns. The VFAs contributed approximately $40-60 \%$ of TOC in tap-water-fed columns, $60-80 \%$ of TOC in the columns fed aerobically pretreated leachate, and up to $70-90 \%$ of TOC in columns fed with anaerobically pre-treated leachate. The feed solution had considerably affected leachate characteristics, and then the build-up of the methanogenesis in the refuse column and the composition of fermentation products in the leachate. The success of a bioreactor landfill depends on whether the recycled leachate could yield a favorable methanogenic environment in the top refuse layer, or whether an appropriate pre-treatment is adopted to modify the leachate characteristics.
\end{abstract}

(c) 2004 Elsevier Ltd. All rights reserved.

Keywords: Recirculation; Pre-treatment; Hydrolysis; Methanogenesis

\section{Introduction}

A bioreactor landfill accelerates stabilization of the landfilled municipal solid waste (MSW), enhances meth-

\footnotetext{
* Corresponding author. Tel./fax: +86 2165981383.

E-mail addresses: xhpjk@mail.tongji.edu.cn, solidwaste@, mail.tongji.edu.cn (P.-J. He).
}

ane production, and costs less than conventional landfill with leachate treatment. Theses factors make it an attractive process for urban waste management (Pohland, 1995). Leachate recycling is a key step in successful bioreactor landfill (Mehta et al., 2002; Reinhart et al., 2002). However, independent tests revealed that bioreactor landfill could fail when MSW of different composition from that by Reinhart et al. (2002) was treated (Bae et al., 1998). Restated, direct recycling leachate 
through the landfill inhibits metabolism of organic matter degradation when the volatile acid levels in leachate is high (Veeken and Sergey, 2000; Zhang et al., 2004). Leachate treated using ex situ processes resolves the inhibition problem carried by the hydrolyzed volatile acids (Kim, 2001).

The characteristics of leachate after ex situ treatment are very different from the original leachate, and the characteristics of the changed leachate play an essential role in refuse stabilization. Moreover, the leachate production rate in practice is typically unstable, particularly during the initial stages of stabilization. Other feed solutions, including leachate from other refuse units could be utilized as feed solutions (Barlaz and Reinhart, 2003). However, the understanding of feed solution characteristics on landfill refuse stabilization is lacking. The leachate flows layer by layer in landfill. Therefore, the characteristics of leachate flowing out from an upper layer would affect the stabilization of its lower layers. The spatial evolution of leachate collected in landfill is not fully understood.

The objective of this research is to explore the effects of different feed solutions, including tap water, refuse leachate pre-treated using an aerobic sequential batch reactor (SBR), and refuse leachate pre-treated using an anaerobic upflow filtration bioreactor (UFB), on the stabilization rates of typical refuse collected in Shanghai, China. This refuse contains a high proportion of easily degradable food waste (He, 2002). The goal of this study is also to demonstrate the spatial interconnection of different refuse layers in landfill site, by utilizing three simulated landfill columns linked in a series that allow the leachate to flow from the upper to the lower columns.

\section{Experimental}

\subsection{Fresh refuse}

The refuse tested in this study was prepared based on Shanghai's data for MSW (He, 2002). Its moisture content was $74.5 \%$, mainly due to food waste: its total composition (w/w) was: food waste $(85 \%)$, plastic $(5 \%)$, paper $(7 \%)$, glass $(1.6 \%)$, textiles $(1 \%)$, and metals $(0.4 \%)$. The relatively high proportion of food waste is a characteristic of MSW in China.

\subsection{Feed solution}

The three feed solutions to be prepared for this study were tap water dechlorinated with aeration, aerobically pre-treated leachate with a SBR, and anaerobically pre-treated leachate with an UFB. The leachate was collected from a real refuse landfill. The characteristics of the feed solutions are shown in Table 1. To compensate for the lack of inorganic nutrients, the following chemi- cals were added to the feed solutions: $\mathrm{CaCl}_{2} 27.5 \mathrm{mgl}^{-1}$, $\mathrm{FeCl}_{3} \cdot 6 \mathrm{H}_{2} \mathrm{O} \quad 0.25 \mathrm{mgl}^{-1}, \quad \mathrm{MgSO}_{4} \cdot 7 \mathrm{H}_{2} \mathrm{O} \quad 22.5 \mathrm{mgl}^{-1}$, $\mathrm{KH}_{2} \mathrm{PO}_{4} 8.5 \mathrm{mgl}^{-1}, \mathrm{~K}_{2} \mathrm{HPO}_{4} 21.75 \mathrm{mgl}^{-1}, \mathrm{Na}_{2} \mathrm{HPO}_{4}$. $7 \mathrm{H}_{2} \mathrm{O} 33.4 \mathrm{mgl}^{-1}$, and $\mathrm{NH}_{4} \mathrm{Cl} 1.7 \mathrm{mgl}^{-1}$.

As show in Table 1, the main differences between the three feed solutions were their alkalinity, DO level, and the levels of methanogenic bacteria. Tap water tests provided a basis for further comparison with low alkalinity and high DO. The alkalinity of effluent from SBR was close to $3000 \mathrm{mgl}^{-1}\left(\mathrm{mgl}^{-1}\right.$ as $\left.\mathrm{CaCO}_{3}\right)$. The effluent from UFB had a high alkalinity and contained methanogenic bacteria.

\subsection{Experiment procedure}

The simulated landfill columns were made of PVC plastic with an inner diameter of $9 \mathrm{~cm}$ and height of $30 \mathrm{~cm}$. A $2-\mathrm{cm}$ height leachate drainage layer made of crockery balls of diameter 5-6 $\mathrm{mm}$ was placed at the bottom of each column. Above this layer there was a fresh 15-cm-high MSW layer that was packed at a density of $800 \mathrm{~kg} \mathrm{~m}^{-3}$. Above this refuse layer was a layer of textiles that evenly distributed the feed solution. The textile was covered with a $1.5-\mathrm{cm}$ gravel layer to prevent the refuse from floating.

The three identical columns were connected in a series. The feed solution was fed into the top of Column 1. All leachate collected at the column's bottom was fed to the top of Column 2. Then the leachate collected at the bottom of Column 2 was fed into the top of Column 3. Gas meters to measure landfill gas and collecting ports to collect leachate were installed on each column. The leachate collected from the top of each of the three columns was named Q1 to Q3 for tap water, H1 to H3 for pre-treated effluent from SBR, and Y1 to Y3 for pretreated effluent from UFB, respectively.

All tests were conducted at $35^{\circ} \mathrm{C}$. The leachate was fed into Column 1 at the same time once a day, at a surface loading of $23.6 \mathrm{~mm} \mathrm{~d}^{-1}$. The surface loading was reduced to $11.8 \mathrm{~mm} \mathrm{~d}^{-1}$ on day 80 for the UFB solution, on day 90 for the SBR solution, and day 100 for tap water. The permeability of leachate flowing through the refuse was estimated at $1.2 \times 10^{-3} \mathrm{~cm} \mathrm{~s}^{-1}$, leading to a retention time of leachate in each column of $3-4 \mathrm{~h}$.

A leachate sample was collected from the bottom of each column twice a week. The $\mathrm{pH}$ of leachate was measured using a PHS-25 pH meter. The leachate's total carbon (TC), total organic carbon (TOC) and inorganic carbon (IC) were measured with an Analytik jena Multi N/C 3000 meter (Germany). Acetic acid, propionic acid, and butyric acid in leachate were measured with a gas chromatograph (GC122M) equipped with a flame ionization detector (FID) and a 30-m Dikma Capillary Column. The temperatures for injection port, the oven, and the FID were at $120^{\circ} \mathrm{C}, 200^{\circ} \mathrm{C}$, and $200^{\circ} \mathrm{C}$, respectively. Total amount of acetic acid, propionic acid, and butyric 
Table 1

Characteristics of the feed solutions

\begin{tabular}{|c|c|c|c|c|c|c|c|c|}
\hline Index & $\begin{array}{l}\text { TOC } \\
\left(\mathrm{mgCl}^{-1}\right)\end{array}$ & $\begin{array}{l}\mathrm{TN} \\
\left(\mathrm{mgl}^{-1}\right)\end{array}$ & $\mathrm{pH}$ & $\begin{array}{l}\text { TP } \\
\left(\mathrm{mgl}^{-1}\right)\end{array}$ & $\mathrm{BOD}_{5} / \mathrm{COD}$ & $\begin{array}{l}\text { Alkalinity } \\
\left(\mathrm{mgl}^{-1} \text { as } \mathrm{CaCO}_{3}\right)\end{array}$ & $\begin{array}{l}\text { DO } \\
\left(\mathrm{mgl}^{-1}\right)\end{array}$ & $\mathrm{MB}^{\mathrm{a}}$ \\
\hline Tap water & 0 & 0 & 6.6 & 0 & NA & Low & $\approx 5.0$ & No \\
\hline Effluent from SBR & $50-70$ & $\approx 0$ & $8.5-8.7$ & $\approx 0$ & 0.2 & $2900-3050$ & $0.1-0.2$ & No \\
\hline Effluent from UFB & $170-190$ & $240-280$ & $8.6-8.8$ & $140-170$ & 0.3 & $6300-6800$ & $\approx 0$ & Yes \\
\hline
\end{tabular}

${ }^{\text {a }}$ Methanogenic bacteria.

acid were calculated and summed as the VFAs. The values of VFAs were expressed as carbon. Alkalinity was analyzed according to Standard Methods (State Environmental Protection Administration of PR China, 1989). To further illustrate the possible role of leachate alkalinity, the so-called "methane alkalinity", determined by titrating the leachate at $\mathrm{pH} 6$ since methanogenesis is generally inhibited at a $\mathrm{pH}$ level below 6 (Lay et al., 1997), was measured.

The contents of methane and of carbon dioxide in biogas samples were analyzed using a gas chromatograph (GC102M) equipped with a thermal conductivity detector and a 2-m stainless column packed with activated carbon.

\section{Results and discussion}

\subsection{Tap water tests: $Q 1-Q 3$}

The time evolutions of TOC in the three leachate streams Q1 to Q3 are similar. The TOC concentrations in leachate first dropped from a high concentration, and then followed an increasing-decreasing curve. TOC concentrations peaked following the sequence of Q3, Q2 and Q1, with their peak TOC values being $6800 \mathrm{mgCl}^{-1}, 4600 \mathrm{mgCl}^{-1}$ and $2800 \mathrm{mgCl}^{-1}$, respectively (Fig. 1a). The TOC peak for Q1, Q2 and Q3 occurred on days 38,42 , and 48 , respectively. Since the retention time of the fed leachate was about $4 \mathrm{~h}$ for each column, this time lag between peak times was not attributable to hydrodynamic dispersion. On the contrary, the hydrolysis of refuse was affected by the leachate TOC levels, with a lower hydrolysis rate corresponding to a higher TOC level. If the hydrolyzed TOC could not be effectively degraded in the refuse layer, the leachate TOC could reach a very high level after passing through several refuse columns. This observation interprets the rather strong leachate noted in practical landfill site.

Before day 30, the VFA levels in Q1-Q3 were close and all were lower than $1750 \mathrm{mgCl}^{-1}$. The VFAs in Q2 and Q3 then increased considerably over time, but those VFAs in Q1 remained unchanged (Fig. 2a). The VFA concentrations in Q2 and Q3 peaked on day 40,
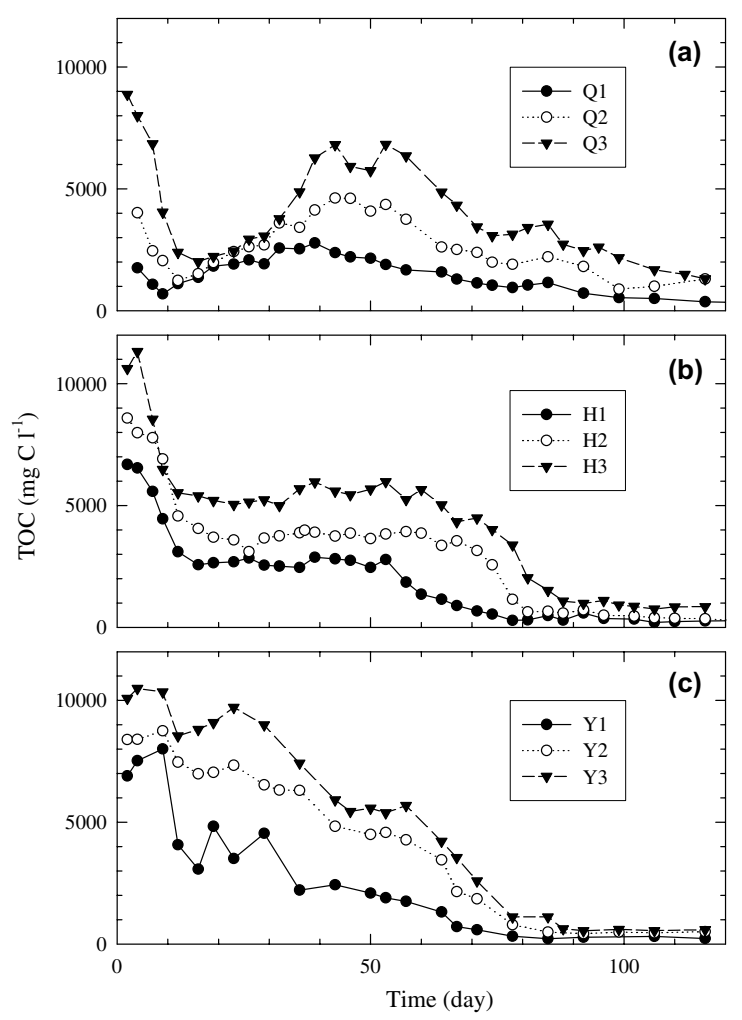

Fig. 1. Time evolutions of the testing leachate's TOC concentrations.

and then dropped gradually over time. A comparison of Figs. 1a and 2a showed that the level of VFAs changed before TOC.

The $\mathrm{pH}$ value of $\mathrm{Q} 1$ ranged from 5.0 to 5.8, while that of Q2 and Q3 fluctuated between 4.7 and 5.0 (Fig. 3a). This occurrence is a natural result of hydrolysis and acidification of refuse (Kim, 2001). The early release of VFAs suggested that the $\mathrm{pH}$ value of leachate would be affected once the hydrolysis reaction occurred in the refuse layer. Since buffer capability of tap water is minimal, a small amount of hydrolyzed VFAs considerably reduced the $\mathrm{pH}$ of the leachate (Fig. 3a). The corresponding methane production rate was low (Fig. 4a). 


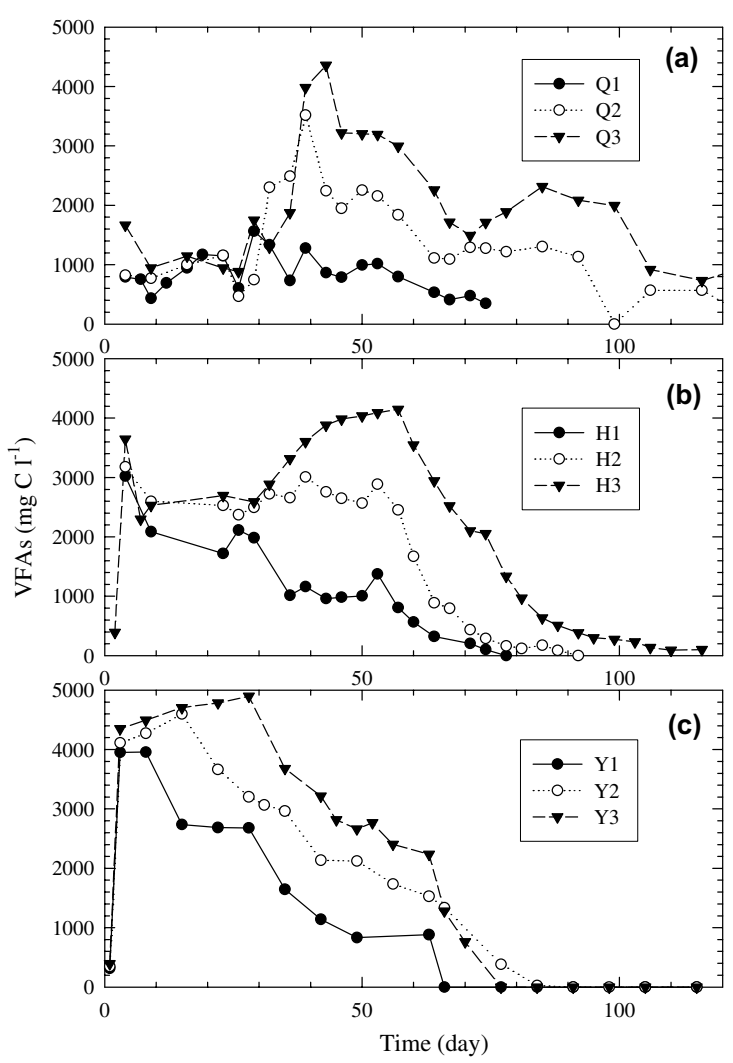

Fig. 2. Time evolutions of the testing leachate's VFA concentrations.

\subsection{SBR solution tests: $H 1-H 3$}

Tests of effluent from SBR showed that TOC concentrations in $\mathrm{H} 1-\mathrm{H} 3$ first increased dramatically and then decreased. During day 16-54 of test, the TOC concentrations in the three columns increased sequentially and then remained at their respective plateau values (Fig. 1b). After day 60, the TOC concentrations for all the three columns gradually decreased.

The change in VFAs for $\mathrm{H} 1-\mathrm{H} 3$ approached a plateau or slightly increased over the period day 10-60. The VFA levels then dropped gradually over time. Most VFAs in $\mathrm{H} 1, \mathrm{H} 2$, and $\mathrm{H} 3$ were consumed after days 78 , 92 , and 105 , respectively.

Prior to day 40 , the $\mathrm{pH}$ value of $\mathrm{H} 1(5.1-5.8)$ was slightly higher than those of $\mathrm{H} 2$ and $\mathrm{H} 3$ (4.7-5.5) (Fig. 4b). Hence, the hydrolysis in columns $\mathrm{H} 2$ and $\mathrm{H} 3$ was also intensive and not inhibited by the leachate that flowed from H1. The increasing methane production rate showed that methanogenic reactions were established in the three columns (Fig. 4b).

From day 40 the $\mathrm{pH}$ value in all the three columns started to increase, and reached a value of 8 for $\mathrm{H} 1$,

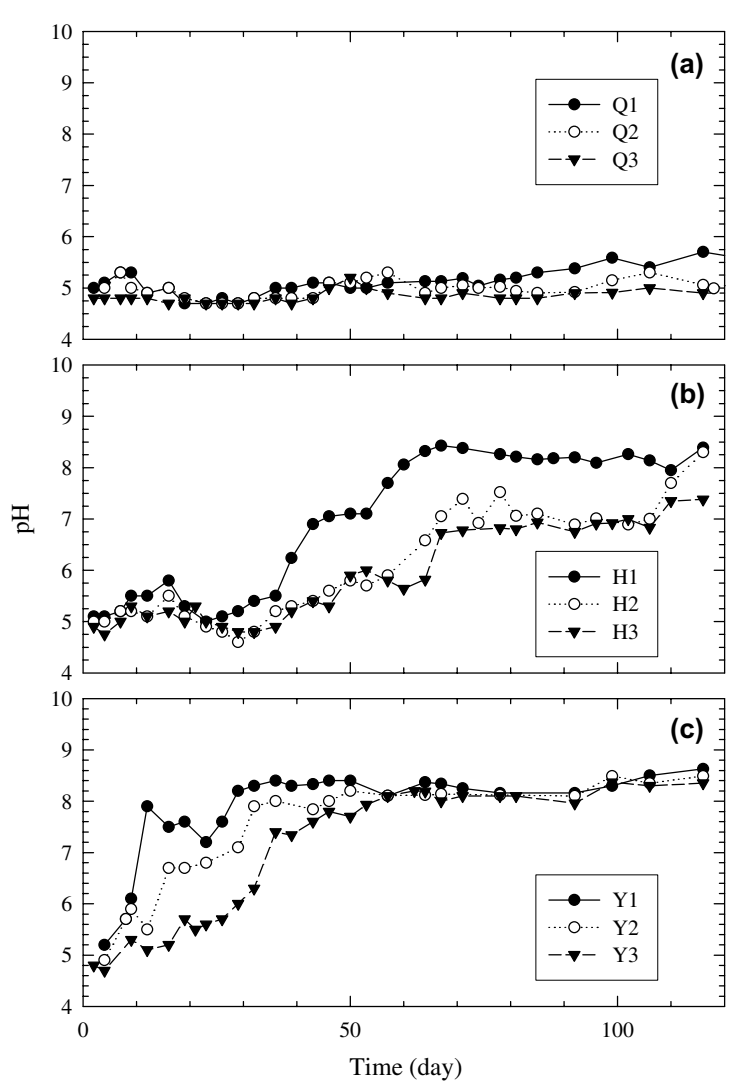

Fig. 3. Time evolutions of the testing leachate's $\mathrm{pH}$ concentrations.

and 7 for $\mathrm{H} 2$ and $\mathrm{H} 3$ on day 65 and onward. The methane production rate ranged from 5 to $40 \mathrm{mgCd}^{-1}$ (Fig. 4b). After day 80, all three columns had established their methanogenic phases.

\subsection{UFB solution tests: $Y 1-Y 3$}

Tests of effluent from UFB showed TOC concentrations in $\mathrm{Y} 1-\mathrm{Y} 3$ decreased over time, following Y3 $>$ Y2 > Y1 (Fig. 1c). The changes in VFAs (Fig. 2c) closely followed that the changes in TOC. The VFAs concentrations of Y1, Y2 and Y3 peaked at 3960, 4600, and $4900 \mathrm{~m} \mathrm{Cl}^{-1}$, respectively. However, the influence of the TOC levels on the hydrolysis of the refuse was not as clear as with Q1-Q3. This occurrence could be attributable to the high alkalinity and $\mathrm{pH}$ of the UFB feed solution.

The $\mathrm{pH}$ values for $\mathrm{Y} 1, \mathrm{Y} 2$ and $\mathrm{Y} 3$ increased over time, reaching a pH value of 8 on day 28,32 , and 57 , respectively (Fig. 3c). The methane production reached a plateau regime with Y3 > Y2 > Y1 (Fig. 4c) over days 75-92, whose magnitudes were higher than $\mathrm{H} 1-\mathrm{H} 3$. 


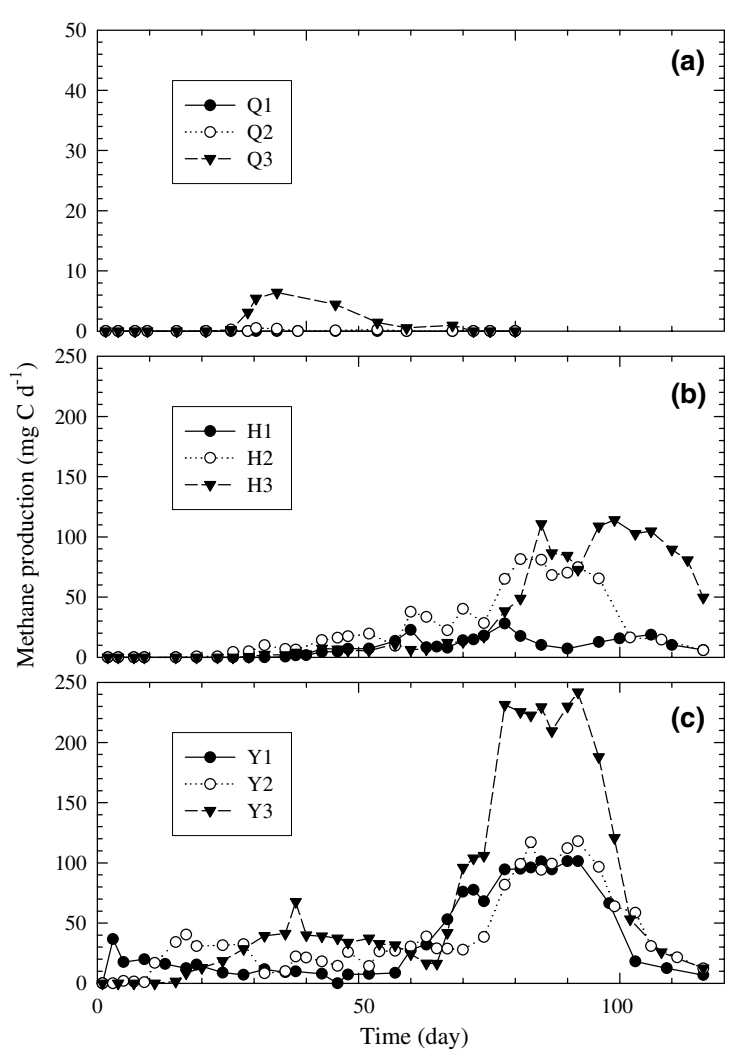

Fig. 4. Time evolutions of methane productions of different simulated landfills.

\section{Discussion}

When the feed solution seeped through the three columns in the series, the reactions that occurred in the first column affected reactions in the subsequent columns. This observation also revealed that the situation noted in the field: the leachate produced from a refuse layer or feed solution from the top layers influenced the dynamic behavior of its lower layers. Restated, the dynamics noted in the current three-column test can be regarded as a schematic version of Shanghai's real landfill site.

Over a refuse column balance of leachate TOC is stated as follows:

$$
\begin{aligned}
& (\text { TOC out })-(\text { TOC in })+(\text { TOC consumed }) \\
& -(\text { hydrolyzed TOC })=0
\end{aligned}
$$

where the term TOC consumed includes the organic carbon assimilated by microbes, transformed into gas phase (i.e., $\mathrm{CH}_{4}$ and $\mathrm{CO}_{2}$ ) and those lost in sampling. Hence, the amount of TOC hydrolysis was estimated as all the other terms in Eq. (1) were experimentally measured.

Columns fed tap water showed slow hydrolysis rates that peaked after 60 days of testing (arrow in Fig. 5a).

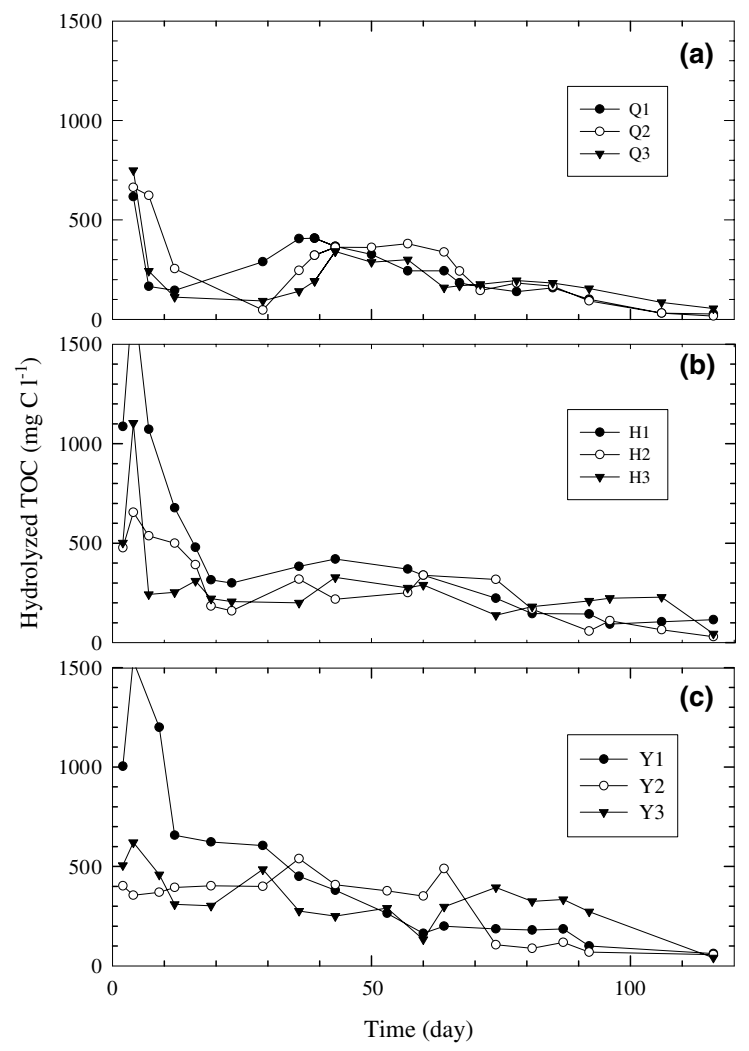

Fig. 5. Time evolutions of hydrolyzed TOC in different simulated landfills.

Moreover, during the initial stage, hydrolysis in column Q1 was much faster than that in columns Q2 and Q3. The acidic environment ( $\mathrm{pH} 4.8-5.4$ in Fig. 3a) therefore delayed refuse hydrolysis. The acidic environment inhibited methanogenesis in the refuse. The high DO concentration $\left(5 \mathrm{mgl}^{-1}\right)$ in the fed tap water also inhibited methane production. Both factors led to a low rate of methane production (Fig. 4a).

When the leachate pre-treated by SBR was fed into the columns, the TOC hydrolysis rates declined rapidly over the first ten days, then fluctuated in a range from 200 to $400 \mathrm{mg} \mathrm{d}^{-1}$ from day 10 to day 75 (Fig. 5b). The difference between hydrolysis rates in various columns was minor. With an intermediate alkalinity and low DO level, the fed SBR solution stimulated the methanogenesis in the refuse column. This occurrence was attributable to the buffer capability of feed solution to neutralize the $\mathrm{H}^{+}$produced during refuse hydrolysis. The H1 started to produce methane later than $\mathrm{H} 2$ and $\mathrm{H} 3$, and also at a lower rate, most likely because the DO level at $0.1-0.2 \mathrm{mgl}^{-1}$ was sufficient to depress activity of methanogenic bacteria.

After the leachate pre-treated by UFB was fed into the column, the hydrolysis rate for the column Y1 
ranged from 250 to $600 \mathrm{mgd}^{-1}$ up to day 60 , was faster than the rates in Y2 and Y3. Although the VFAs were rapidly produced (Fig. 2c), the high alkalinity still effectively neutralized the $\mathrm{pH}$ of leachate (Fig. 3c). The high alkalinity and methanogenic bacteria in the feed solution also led to early methanogenesis in column $\mathrm{Y} 1$, and stimulated methane production in column $\mathrm{Y} 2$ and $\mathrm{Y} 3$, following the sequence Y1 to Y2 to Y3. The UFB effluent enhanced hydrolysis and methanogenesis in the refuse layer.

Table 2 lists the alkalinity data and the "methane alkalinity" of collected samples. The changes of both alkalinities corresponded to each other. The methane alkalinity of tap water was low, following Q3 $>$ Q2 $>$ Q1, and was gradually consumed during testing. With SBR effluent as the feed solution, the methane alkalinity for $\mathrm{H} 1-\mathrm{H} 3$ was 3 to 5 times higher than that for Q1-Q3 and remained unchanged over the duration of the test. The methane alkalinity of Y1-Y3 was 2 to 3 times higher than that of $\mathrm{H} 1-\mathrm{H} 3$, and dropped when the methanogenesis entering an intensive state (days $70-90$ for Y1-Y3). The levels of both alkalinities were continuously recovered as a consequence of effective methanogenesis.

Fig. 6 shows the time evolution of the accumulation of hydrolyzed TOC in Q1, H1 and Y1. Up to day 116 the accumulation of the hydrolyzed TOC reached 24.6, 38.8, and 40.0 g in Q1, H1, and Y1, respectively. Differ-

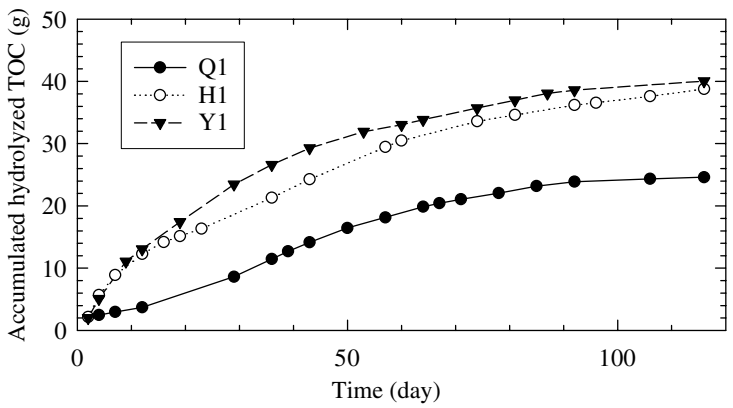

Fig. 6. Time evolutions of the accumulated hydrolyzed TOC.

ent feed solutions affected the hydrolysis rate of refuse (also in Fig. 5). Comparing with the tap-water fed column, the capability to neutralize $\mathrm{pH}$ using SBR solution with high alkalinity could increase the accumulated, hydrolyzed TOC by $14.2 \mathrm{~g}$ (from $24.6 \mathrm{~g}$ to $38.8 \mathrm{~g}$ ). An even higher alkalinity in the UFB solution could only increase another $1.2 \mathrm{~g}$ in accumulated hydrolyzed TOC (from $38.8 \mathrm{~g}$ to $40 \mathrm{~g}$ ).

Also noticeable in Table 3, and Figs. 1 and 2, the VFAs contributed $40 \%$ to $60 \%$ of the TOC in Q1-Q3, while the VFAs contributed $60-80 \%$ for $\mathrm{H} 1-\mathrm{H} 3$, and up to $70-90 \%$ for $\mathrm{Y} 1-\mathrm{Y} 3$. The VFA production rate followed both acetic acid $>$ butyric acid $>$ propionic acid, and $\mathrm{Y} 1>\mathrm{H} 1>\mathrm{Q} 1$. Therefore, different feed solutions

Table 2

Time evolution of alkalinity and methane alkalinity of the leachate ${ }^{\mathrm{a}}$

\begin{tabular}{|c|c|c|c|c|c|c|}
\hline \multirow[t]{2}{*}{ Time (d) } & \multicolumn{2}{|l|}{ Q1 } & \multicolumn{2}{|l|}{ Q2 } & \multicolumn{2}{|l|}{ Q3 } \\
\hline & Methane alkalinity & Alkalinity & Methane alkalinity & Alkalinity & Methane alkalinity & Alkalinity \\
\hline 12 & 210 & 930 & 430 & 2030 & 870 & 3650 \\
\hline 29 & 110 & 900 & 400 & 1870 & 720 & 3360 \\
\hline 56 & 170 & 970 & 570 & 2720 & 670 & 3760 \\
\hline 78 & 260 & 750 & 730 & 1920 & 930 & 2560 \\
\hline 102 & 140 & 410 & 370 & 1400 & 560 & 2080 \\
\hline \multirow[t]{2}{*}{120} & 220 & 450 & 400 & 1680 & 580 & 2030 \\
\hline & \multicolumn{2}{|l|}{$\mathrm{H} 1$} & \multicolumn{2}{|l|}{$\mathrm{H} 2$} & \multicolumn{2}{|l|}{ H3 } \\
\hline 12 & 1870 & 3600 & 2680 & 4350 & 2860 & 4580 \\
\hline 29 & 2430 & 3330 & 3070 & 4020 & 3200 & 5010 \\
\hline 56 & 1700 & 3950 & 3020 & 4320 & 3900 & 4800 \\
\hline 78 & 2230 & 3570 & 3560 & 3600 & 3750 & 5210 \\
\hline 102 & 2420 & 3430 & 2365 & 4030 & 3660 & 4400 \\
\hline \multirow[t]{2}{*}{120} & 3010 & 3330 & 2650 & 4430 & 4000 & 4560 \\
\hline & \multicolumn{2}{|l|}{ Y1 } & \multicolumn{2}{|l|}{ Y2 } & \multicolumn{2}{|l|}{ Y3 } \\
\hline 17 & 7370 & 18520 & 8250 & 20550 & 10200 & 25640 \\
\hline 51 & 5600 & 7980 & 6890 & 9130 & 7210 & 11020 \\
\hline 72 & 6210 & 10070 & 6850 & 12200 & 7020 & 12370 \\
\hline 91 & 6990 & 7560 & 7210 & 8890 & 7230 & 9690 \\
\hline 102 & 7360 & 8940 & 7560 & 9030 & 8020 & 10002 \\
\hline 120 & 10200 & 12250 & 11270 & 12690 & 10230 & 11690 \\
\hline
\end{tabular}

\footnotetext{
${ }^{\mathrm{a}}$ Unit: $\mathrm{mgl}^{-1}$ as $\mathrm{CaCO}_{3}$.
} 
Table 3

Maximum ratios of VFAs to TOC in Q1, H1 and Y1

\begin{tabular}{lllr}
\hline & Q1 & H1 & Y1 \\
\hline VFAs $\left(\mathrm{mg} \mathrm{Cl}^{-1}\right)$ & 1170 & 1980 & 2740 \\
TOC $\left(\mathrm{mgCl}^{-1}\right)$ & 1820 & 2550 & 3070 \\
VFAs/TOC & 0.64 & 0.78 & 0.89 \\
\hline
\end{tabular}

altered the hydrolyzed products in the leachate (Fig. 7). The VFAs concentration for Q1 peaked on day 40, and acetic acid reached $800 \mathrm{mgCl}^{-1}$, and the propionic acid reached less than $240 \mathrm{mgCl}^{-1}$. The acetic acid in $\mathrm{H} 1$ peaked at $1200 \mathrm{~m} \mathrm{Cl}^{-1}$ on day 24 , and both propionic and butyric acids declined from $800 \mathrm{mgCl}^{-1}$. The acetic acid production for UFB effluent could reach up to $1600 \mathrm{mgCl}^{-1}$ on day 10 , and butyric acid reached $1530 \mathrm{mgCl}^{-1}$. Acetic acid had a higher concentration than propionic acid and butyric acid over the first 70 days in Q1, H1, and Y1, with the butyric acid having a slightly higher concentration than propionic acid. The acetic acid concentration dropped to zero faster that of butyric acid, and the concentration of butyric acid dropped faster than that of propionic acid. Hence, the feed solutions impacted the hydrolysis rate (Fig. 2) as well as the composition of the fermentative products. The high acetic acid concentration and a high $\mathrm{pH}$ buffer capacity produced a favorable environment for methanogenesis.

Carbon transfer ratio to gas phase was defined as follows: gas transfer ratio

$$
=\frac{\sum \text { carbon in gas }}{\sum \text { carbon in leachate }+\sum \text { carbon in gas }} \times 100
$$

Up to day 116, gas transfer ratios for columns fed with SBR effluent and UFB effluent were 23\% and $38 \%$, respectively. While gas transfer ratio for the columns fed with tap water was only $4 \%$. The strong leachate noted in typical landfill sites was produced by an intense hydrolysis reaction without sufficient methanogenesis in the refuse. The ratio of carbon transfer to gas phase was used as a preliminary quantitative index to assess the effects of feed solutions. The capability to neutralize $\mathrm{pH}$ with high alkalinity and a reduced oxygen level increased the conversion ratio by $19 \%$ (4-23\% for SBR). The presence of methanogenic bacteria and the further depletion of oxygen in the feed solution increased the conversion ratio to $23-38 \%$ with UFB solution.

These results clearly revealed that the leachate characteristics in a bioreactor landfill should be modified to improve degradation of organic matter. The hydrolysis and methanogenesis in the top layer of refuse that receives the recycled or fed leachate would be directly influenced, as would the hydrolysis rates and the hydrolyzed products, with the environments of the lower layers subsequently affected. When the refuse contains a great proportion of easily hydrolyzed components, such as in the case of Shanghai's refuse, the pre-treatment of leachate becomes an indispensable step for successful
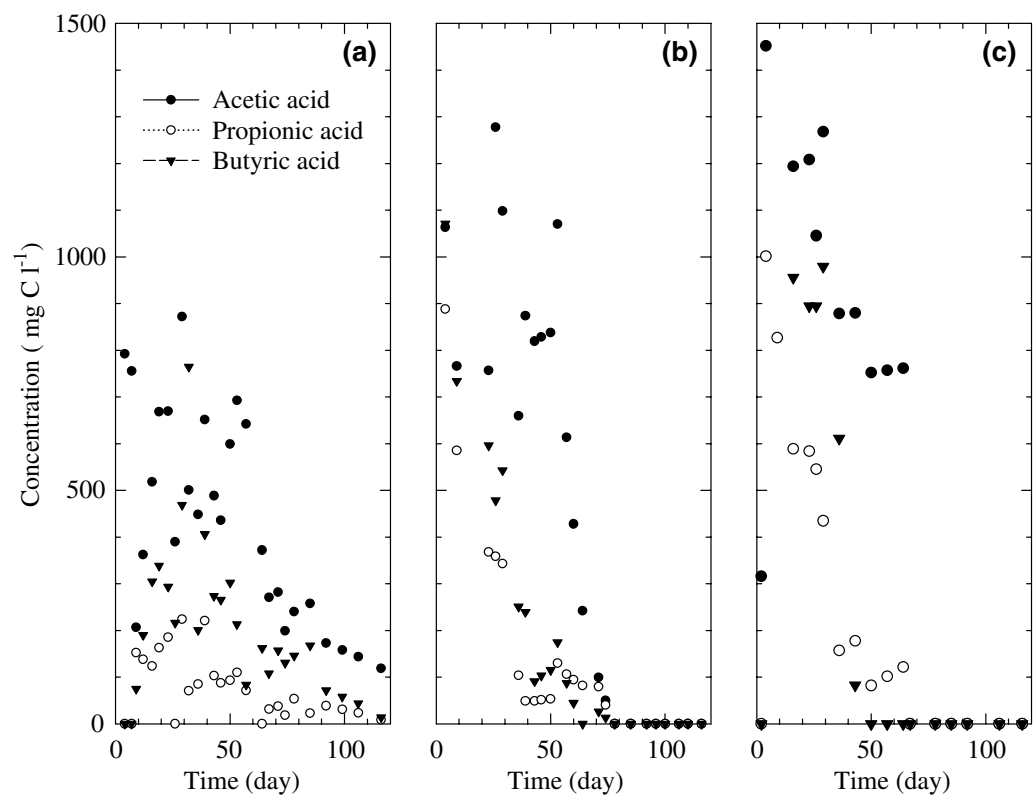

Fig. 7. Time evolutions of acetic acid, propionic acid, and butyric acid in (a) Q1, (b) H1, (c) Y1. 
operation of a bioreactor landfill. In this study, anaerobic pre-treatment was the best option among those investigated since it produced high alkalinity for neutralizing the $\mathrm{pH}$ value of the leachate, and provided methanogenic bacteria for early methanogenesis in the top refuse layer.

\section{Conclusions}

This study examined the effects of feed solutions on the hydrolysis and methanogenesis in a refuse landfill. The alkalinity, dissolved oxygen level, and presence of methanogenic bacteria in a feed solution considerably affected the hydrolysis rate and establishment of methanogenesis in the top refuse layer. The leachate that flowed out of the first layer influenced the layers below. For the columns fed with dechlorinated tap water, the hydrolysis rate of refuse followed a bell curve and peaked following the sequence of Q3 (top column), Q2 and Q1 (bottom column); the peak TOC values for Q3, Q2 and Q1 were $6800 \mathrm{mgCl}^{-1}, 4600 \mathrm{mgCl}^{-1}$ and $2800 \mathrm{mg} \mathrm{Cl}^{-1}$, respectively. The $\mathrm{pH}$ value for $\mathrm{Q} 1$ ranged from 5.0 to 5.8, while the $\mathrm{pH}$ values for Q2 and Q3 fluctuated between 4.7 and 5.0. Hence, methanogenesis was inhibited and a strong leachate was discharge from the bottom layer. Direct adding tap water to the refuse layer did not assist in the refuse stabilization because of low buffer capability of leachate. The columns fed with aerobically pre-treated leachate $(\mathrm{H} 1-\mathrm{H} 3)$ yielded a higher hydrolysis rate. After day 40 the $\mathrm{pH}$ value over the three columns started to increase, reaching 8 for $\mathrm{H} 1$, and 7 for $\mathrm{H} 2$ and $\mathrm{H} 3$ on day 65 and afterward. The methane content in biogas increased to $40-60 \%$. The corresponding hydrolysis rates for anaerobically pre-treated leachate (Y1-Y3) were the highest among the three feed solutions. The strong buffer capacity of the UFB solution yielded a $\mathrm{pH}$ value of 8 for $\mathrm{Y} 1, \mathrm{Y} 2$, and $\mathrm{Y} 3$ on day 28,32 , and 57 , respectively. The corresponding methane content increased to about $70 \%$ after day 80 .

The chemical environment in the top refuse layer was dramatically affected by the characteristics of the feed solutions. The hydrolysis rates for the top layer were much faster than those for the lower layers. Without an appropriate buffer capacity, the methanogenic reaction in the lower columns was inhibited. Once the leachate's $\mathrm{pH}$ was neutralized with a high-alkalinity feed solution, early methanogenesis occurred and stimulated methanogenesis in the lower refuse layers. The VFAs accounted for $40-60 \%$ of the TOC in Q1-Q3; while those for H1$\mathrm{H} 3$ for $60-80 \%$; and $\mathrm{Y} 1-\mathrm{Y} 3$, up to $70-90 \%$ of TOC, respectively. The VFA production rate followed acetic acid $>$ butyric acid $>$ propionic acid, and $\mathrm{Y} 1>\mathrm{H} 1>$ Q1. Therefore, different feed solutions also changed the hydrolyzed products in the leachate. After 120 days of testing with these three feed solutions, the carbon in re- fuse was converted to gas phase by $4 \%, 23 \%$, and $38 \%$, respectively. The success of bioreactor landfill depends on whether the recycled leachate could produce a favorable methanogenic environment at the top refuse layer or whether an appropriate pre-treatment has been adopted to modify the leachate's characteristics.

\section{Acknowledgment}

Support for this work by the Hi-Tech Research and Development Program (no. 2001AA644010, 2003AA644020) of China and the Key Subject Project (environmental engineering) of Shanghai, is gratefully appreciated.

\section{References}

Bae, J.H., Cho, K.W., Lee, S.J., Bum, B.S., Yoon, B.H., 1998. Effects of leachate recycle and anaerobic digester sludge recycle on the methane production from solid wastes. Water Sci. Technol. 38, 159-168.

Barlaz, M., Reinhart, D.R., 2003. Editorial. Waste Manage. 23, 557-559.

He, P.J., 2002. The Research on the Feasibility of the 4th Stage Project of the Laogang MSW Landfill in Shanghai, PR China. Shanghai City Appearance and Environmental Sanitary Administrative Bureau, PR China.

Kim, J., 2001. A Bioreactor Landfill Incorporating Innovations in Leachate and Gas Management with a Dedicated Treatment Zone. PhD thesis. University of Pittsburgh, Pennsylvania, USA.

Lay, J., Li, Y., Noike, T., 1997. Influences of $\mathrm{pH}$ and moisture content on the methane production in high-solids sludge digestion. Water Res. 31, 1518-1524.

Mehta, R., Barlaz, M.A., Yazdani, R., Augenstein, D., Bryars, M., Sinderson, L., 2002. Refuse decomposition in the presence and absence of leachate recirculation. J. Environ. Eng. ASCE 128, 228-236.

Pohland, F.G., 1995. Landfill bioreactor: historical perspective, fundamental principles, and new horizons in design and operations. Paper from Proc. Landfill Bioreactor Design and Operation Seminar held in Wilmington, DE, USA, EPA/600/R-95/146, US Environmental Protection Agency, pp. $9-24$.

Reinhart, D.R., McCreanor, P.T., Townsend, T., 2002. The bioreactor landfill: its status and future. Waste Manage. Res. 20, 172-186.

State Environmental Protection Administration of PR China, 1989. Methods for Monitor and Analysis of Water and Wastewater, third ed. China Environmental Science Press, Beijing.

Veeken, A., Sergey, K., 2000. Effect of pH and VFA on hydrolysis of organic solid waste. J. Environ. Eng. ASCE 126, 1076-1081.

Zhang, X.X., He, P.J., Shao, L.M., Li, G.J., 2004. Effects on landfill methane production by different leachate recirculation operations. ACTA Sci. Cir. 24, 304-308. 